\title{
Professor Critical Reflection and its Impact on Learning Environments: A Case Study Applied to a First-year Mathematics Course in Engineering
}

\author{
Dr. Norha M. Villegas, Universidad Icesi, Colombia - University of Victoria, Canada
}

Norha M- Villegas is an Associate Professor in the Department of Information and Communication Technologies, Director of the Software Systems Engineering Bachelor Program at Universidad Icesi, Cali, Colombia, an Adjunct Assistant Professor of the Department of Computer Science, University of Victoria, in Canada, and an IEEE Senior Member. Her research interests include engineering education, contextmanagement, cyber physical systems, context-aware analytics, self-adaptive and self-managing systems, and runtime software evolution. She conducted her PhD at University of Victoria, between September 2009 and February 2013. In November 2011 she received the IBM Canada CAS Research Project of the Year 2011 for the application of context-awareness and self-adaptation to the improvement of on-line shopping systems. Over the last ten years she have co-authored an important number of scientific papers on software engineering, co-chaired several international workshops and conferences, and served in an important number of program committees for international conferences such as the International Conference on Software Engineering (ICSE) and the International Conference on Software Maintenance and Evolution (ICSME). She is the leader of the continuous improvement and accreditation processes for the Software Systems Engineering bachelor program of Universidad Icesi in Colombia.

\section{Mrs. Stephanie Celis Gallego, Universidad Icesi}

She has a degree in mathematics from Universidad Santiago de Cali, a master's degree in mathematics education from Universidad del Valle and she is a specialist in university teaching at Icesi University. She has worked as a teaching coach for the public sector and advisor of pedagogical projects led by Universidad del Valle and the National Ministry of Education, with more than ten years of experience as a high school teacher at Colegio Bolivar. Her contributions in research in mathematics education, have focused mainly on the levels of difficulty associated with learning of school algebra, she has also led initiatives that contribute to inclusive curricular designs, based on the use of skills.

\section{Mrs. Ivonne María Suárez, Universidad Icesi}

Mathematics of the National University of Colombia, Bogota D.C. and Master in Education, with Emphasis in Research and Concentration in Education in Science, Technology, Engineering and Mathematics (CTIM) of the Universidad de los Andes. I am characterized by being rigorous, autonomous and committed to my work, I have ten years of experience in the education sector and I have worked in the following lines of work: 1. teacher training and teaching managers, 2. education in mathematics, science and technology (engineering), 3. the evaluation of / for the / and as learning, 4. the design, revision and / or adaptation of didactic or instructional materials, and 5. pedagogical advice in research and innovation in the classroom (docents practices). Currently, I am a consultant and my topics of interest are the research in the classroom, particularly the study of teaching practices as generators of networks and learning communities, the relationships between science, technology, society and culture, and the evaluation of programs and educational policies. I believe that my biggest contribution to education has been to design, implement and evaluate learning scenarios as a teacher and teacher educator and teaching directors in different regions of the country.

\section{Ing. Juliana Jaramillo JJO, Universidad Icesi}

I'm an Industrial Engineer that works in high education with Interest in management, assessment and evaluation curricular that assurance the learning outcomes. During my undergraduate of Industrial Engineering, I questioned about teaching and learning, especially in academic failure and your impact on the process of learning.

Now, I working to assurance learning outcomes to six undergraduate programs of engineering of a Latin American University located in Colombia. The school at present have four undergraduate programs in engineering and two in design. Three of four programs have ABET accreditation.

The next project is working with the graduate programs in the school to firm up the assurance of learning. 


\section{Dr. Angélica Burbano, Universidad Icesi}

Angelica Burbano C., holds a Ph.D. in Industrial Engineering from the University of Arkansas. She holds a MSOM from Universidad Icesi and a BS in industrial engineering from Pontificia Universidad Javeriana both in Cali, Colombia. She is a Fulbright Scholar 2007 and a fellow AOTS, Japan 2000. She is a senior member of IISE. Angelica has previous experience (six years) in the food manufacturing industry (experience related to inventory management and production planning and control, also information systems such as ERP). During her studies in the United States she worked a research assistant at the Center for Innovation on Healthcare Logistics CIHL, her work for CIHL focused on assessing the impact of GS1 standards adoption in the healthcare supply chain. Her research interests are related to the adaptation of existing manufacturing and logistics models and structures to the healthcare supply chain with a specific focus on medical supplies. She is also interested on engineering education research. She is part of the IE Department at Universidad Icesi since 1998. She has over fifteen years of teaching experience and has served as Director of the Undergraduate program in Industrial Engineering (2003-2007), Director of the Graduate program in Industrial Engineering (2012-2014), and she currently serves as the IE Department Head.

\section{Prof. Alvaro Pachon, Universidad Icesi}

Álvaro Pachón (alvaro@icesi.edu.co) is a professor at the Icesi University, Colombia. He received his B.S. degree in Computer Engineering, in 1990, from Icesi University, his D.E.A. in Information Technologies from Vigo University in 2005, and his Ph.D in Ingeniería Telemática from Vigo University.

\section{Mr. Diego Antonio Bohorquez, Universidad Icesi \\ Ing. Lina Marcela Quintero P.E., Universidad Icesi \\ Ms. Isabel Echeverri, Universidad Icesi \\ Mrs. Lady K. Castillo \\ Prof. Cesár Augusto Cuartas Rodríguez, Universidad Icesi}

Soy el jefe de departamento de matematicas y estadística de la Universidad Icesi. Además, soy docente de los cursos Algebra y fuciones y matemáticas para ecónomia. Mis temas de interés son: Investigación en matemática educativa, didácta de las matemáticas y la tecnología al servicio de la educación. 


\title{
Professor critical reflection and its impact on learning environments: a case study applied to a first year mathematics course in engineering
}

\begin{abstract}
This evidence-based paper presents the results of a case study focused on investigating the impact of faculty continuous critical reflection on learning environments, in the context of a first year mathematics course that is mandatory for engineering students. Findings demonstrate that when instructors reflect about their pedagogical practices and act consequently, most aspects of learning environments improve and, as a result, students' willingness to learn, which in turn generates a positively impact on the attainment of learning objectives.
\end{abstract}

\section{Introduction}

In Colombia, the low performance of students in mathematics courses is one of the main causes of academic attrition in engineering professional programs. Academic desertion has a high impact on society, as well as institutions and student families. One important reason for this situation is that the national education system does not focus on the development of STEM competencies. As a result, the motivation of engineering students in mathematics courses is continuously hampered because of deficiencies in prerequisites. This paper reports partial results from a project conducted in collaboration between mathematics and engineering at Universidad Icesi, in Colombia. The project involves the Algebra and Functions, Linear Algebra, Calculus I, and Probability Theory (Statistics I) courses. The main objective of this project is to support mathematics instructors in the process of improving student learning, by continuously reflecting on the effectiveness of the pedagogical practices that are applied inside and outside the classroom, and adopting a continuous improvement culture that benefit student learning accordingly.

The case study reported in this paper involves two course sections of the Algebra and Functions course that are coordinated by two different professors (at the instructor rank, thus, the terms professor and instructor will be used interchangeably along the paper). One of the professors was mentored during the project (henceforth, the mentored instructor/professor) while the other one was not (henceforth, the non-mentored instructor/professor). The course led by the non-mentored instructor is the control course, while the other one is the treatment course. For the development of each case study, we defined the following stages: i) the mentored instructor identifies a set of learning objectives that have been difficult to attain by the students of the corresponding course. Students were surveyed about learning difficulties in the courses addressed in this project; ii) this instructor is mentored by specialists in mathematics education, who help her in a critical reflective exercise to identify improvement opportunities in what respect to the pedagogical practices that she usually applies in the learning process associated with the set of problematic learning outcomes that were identified in the first stage; iii) the mentors help the instructor in the process of conducting a simple but powerful continuous critical reflection exercise, in which departing from a guiding question and an exploration of relevant literature, the instructor proposes new learning experiences with the goal of improving the learning environment. The design of the new pedagogical experience considers the revision of the learning objectives in light of the corresponding math competencies, the context in which the learning activities are 
developed, and the use of technology for supporting these activities; iv) the mentored instructor implements her new proposed learning experience. External observers gather data by interviewing the participants, as well as recording and observing all sessions.

The main contribution of this paper is to provide faculty with an evidence-based case study that illustrates how powerful is that professors, particularly math professors, acquire a continuous active reflection culture, in such a way that they keep improving their teaching practices and learning environments with the goal of helping their students succeed in their learning processes.

This paper is organized as follows. Section 2 presents theoretical aspects related to the importance of faculty reflection for improving the quality of learning environments. Section 3 details the case study conducted for the Algebra and Functions course, including its methodology and evaluation protocol. Section 5 discusses relevant results. Finally, Section 5 concludes the paper.

\section{The importance of professor reflection on her/his pedagogical practices}

This section presents the theoretical foundations that support the pedagogical component of this project. The main idea is that professors that continuously reflect, individually and collectively, and commit to act accordingly to improve their pedagogical practices, generate a positive impact on the quality of learning environments, which in turn improves students' willingness to learn. Critical reflection is more than simply thinking about something, and in the case of professors, more than thinking about their practices. It implies a disciplined way of identifying what can be improved in their pedagogical practices and find effective mechanisms to achieve these improvements. Therefore, relevant background for this project includes critical reflection, and its relationship with professor professional development and mathematics learning environments.

\subsection{Critical reflection}

Critical reflection is absolutely required to leverage the value of instructor reflection. LawrenceWilkes and Ashmore [1] mention that the 21st century instructor needs skills as social mediator, learning facilitator and reflective practitioner. In particular, the reflective practitioner needs to make intellectual space to develop pedagogic processes for self-directed, contextualized critical reflection, and praxis for inclusive teaching/training and learning [1, p. 27]. Larrivee [2] [cited in 1, p.26-27] uses the term critical reflection to integrate critical inquiry and self-reflection as key attributes of the reflective practitioner. On the one hand, critical inquiry involves the conscious consideration of the moral as well as ethical implications and consequences of classroom practices on students [2, p. 294]. On the other hand, self-reflection goes beyond critical inquiry by adding to conscious consideration the dimension of deep examination of personal values and beliefs, embodied in the assumptions professors make and the expectations they have for students [2, p. 294]. This suggests that professors in general, and in particular mathematics professors, must engage in some aspects of critical reflection that are needed for playing the effective reflective practitioner role [1, p. 27] that is required for guiding students in their learning processes. 


\subsection{Reflective practice and professional development}

Reflective practice is a way of understanding and learning from experiences, it is a resource for helping instructors reflect on pedagogy, as well as improve their personal development and professional practice [1]. Bruce [3] proposes that people should question their level of ability to reflect effectively in order to develop and improve their professional role. Authors such as Brookfield [4] state that it is possible to teach reflectively, while focusing on the basic elements of the classroom process. Dewey [5] mentions that the development of reflective thinking provides a method for going beyond purely impulsive or routine actions. Dunne [6] [cited in 6, p. 418-419] indicates that reflection, self-awareness and self-learning have been more important for experienced leads than the simple acquisition of information. Therefore, professors can benefit tremendously from a continuous critical reflection praxis in the process of improving their pedagogical practices, which in turn constitutes an effective self-training process and a way of achieving their professional satisfaction.

\subsection{Mathematics learning environments}

Kellam et al. proposed a model for learning environments in engineering [7] based on their definition of "complex learning environments." In complex learning environments students cooperate instead of competing. Learning strategies, including in-classroom and out-ofclassroom experiences, go beyond the acquisition of information. In this way, it results possible to assure a continuous information cycle throughout the system that allows students to actively participate in the construction of their own knowledge and skills. Mathematics learning in engineering requires complex learning environments where problems emulate real life scenarios as much as possible, while considering student particular needs. Furthermore, solving authentic problems requires teamwork and the application of suitable technologies and tools, which increase the willingness of students to learn and connect concepts, as well as discuss about and apply what they learn. Finally, an effective mathematics learning environment must conceive the evaluation as the main vehicle to assure a continuous feedback to the process, for the improvement of both professors and students [8].

The development of mathematics competencies is crucial for engineering students. Therefore, professors must conceive pedagogical strategies that help students learn mathematics in practice and in real contexts, as proposed by critical mathematics [9]. Thus, effective mathematics classroom experiences are developed in complex learning environments.

ASOCOLME (Colombian Association of Educational Mathematics) [10] defines classroom experiences as the spaces in which professors orchestrate successful learning experiences, as a result of a systematic reflection on pedagogical practices, that should lead to the implementation of innovative strategies in the teaching of mathematics, derived from a research process, either completed or in development. Thus, this project focuses on evaluating the impact of the critical reflection of mathematics instructors in the learning environment of engineering students. For this, the reflection of the professors involved in the project focusses on the following dimensions: 1) level of achievement of learning objectives; 2) coherence between competencies, learning objectives and contents; and 3) teaching and evaluation strategies, which include learning activities, resources, assessment methods and the coherence among them, as well as the feedback given to students. 


\section{Case study: The Algebra and Functions course}

\subsection{Methodology}

As shown in Figure 1, this case study began with a review and analysis at the micro-curriculum level of the Algebra and Functions syllabus, followed by individual and group support directed by mentors with expertise in the field of mathematics education. In a third and fourth moment, the mentored instructor design and implement the new learning experience. Critical reflection takes place along these first four phases that are mainly conducted by the mentored instructor. Finally, the case study finishes with the evaluation stage, which includes a quantitative and qualitative analysis of the information.

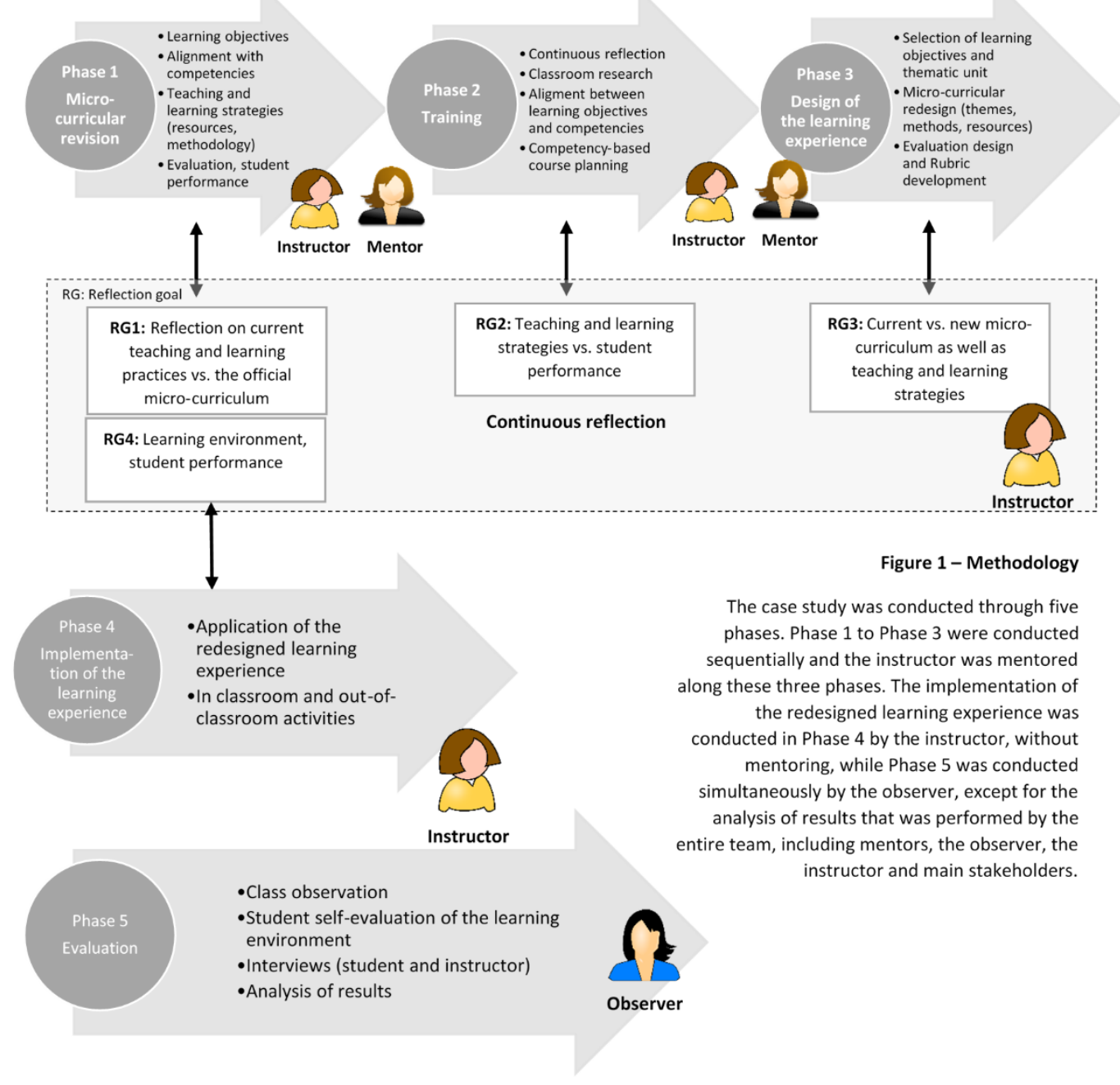

Figure 1 - Methodology

\section{Phase 1. Micro-curriculum analysis}

In this first stage, through the support of an external peer, a review of the official Algebra and Functions syllabus is carried out. For this, some of the main elements involved in a microcurriculum design are taken into consideration, which are related to the analysis of the learning 
objectives, the mathematical contents, the resources, the methodology and the evaluation. This process was consolidated by the mentored instructor by taking into account her pedagogical practices, the findings identified in the syllabus, and the real needs of students in terms of learning mathematics.

\section{Phase 2. Individual and group training}

The mentored instructor participated in workshops related to the role of mathematics professors, the importance of including a continuous critical reflection on pedagogical practices, the formulation of learning objectives and their alignment with disciplinary competencies, the effects of teacher decisions on resources, as well as on designing and planning a new learning experience by following the ideas of backward design [11].

\section{Phase 3. Design of the learning experience}

Based on the inputs received from the previous stages and, most importantly, on her own reflection, the mentored professor was supported in the design of a new learning experience that focused on the development of communication, modeling and problem solving competencies in mathematics. Since the Algebra and Functions course has not been redesigned yet to be compliant with competency-based education, for the case study we based on the mathematical competencies proposed by OECD (Organisation for Economic Cooperation and Development) in its Programme for International Student Assessment (PISA) [12].

The first step in the design of the new learning experiment was the selection of a thematic unit, by taking into account the results of her reflection on the difficulties that she considered recurrent in the learning of mathematics of the majority of students who have enrolled in the course of Algebra and Functions. Afterwards, she defined learning objectives linked to the selected mathematics competencies, proposed activities that corresponded to the learning goals, and defined pedagogical practices and assessment methods (including rubrics) that were different to what she have usually defined for her courses.

\section{Phase 4. Implementation of the classroom experience}

In this phase the mentored instructor executes the plan defined for realizing the new learning experience. The implementation was carried out during four class sessions for a total of 8 hours. The physical space used for this purpose was different from that of the usual class, as the usual classroom had limitations to encourage collective reflection and teamwork.

\section{Phase 5. Evaluation}

In order to evaluate the implementation, we conducted a randomized controlled trial. We selected a random sample of 47 first semester students attending engineering programs (i.e., Software Systems Engineering, Industrial Engineering and Telecommunications Engineering), out of a population of 99, and registered them randomly in two groups: 22 students in the treatment group (the mentored group), and 25 students in the control group (the non-mentored group). These two groups are statistically equivalent in terms of gender, age and engineering 
programs, such that the only difference between them is the instructor and the learning experience.

The evaluation of this case study focuses on 1) the observation of the classroom experiences in both groups by an expert in math education, who was also part of the mentoring team; 2) a selfassessment conducted by the students of both groups about the learning environment; 3 ) interviews applied to the students by the observer; 4) the results of the assessment applied to the students at the end of the thematic unit to measure the level of attainment of the corresponding learning objectives; 4) the reflection conducted by the instructor throughout the case study; and 5) the observations made by the mentors during the process.

The evaluation is supported by three instruments: 1) The diagnosis test, a written test whose purpose was to assess the level of attainment of learning objectives that are prerequisites for the thematic unit associated with the redesigned learning experience. The goal of this instrument was to identify any differences between the two groups of students on what respects to the prerequisites. The results indicate that there were no relevant differences. 2) The instrument to evaluate the learning environment from the perspective of the student, henceforth the LE-Student instrument (adapted from [13]). This instrument was applied once to the students of both groups and evaluates 32 aspects of learning environments through questions carefully defined to be easily answered by first semester engineering students enrolled in Algebra and Functions. And 3 ) the closure test, a written test that was used to assess the level of attainment of the learning objectives associated with the redesigned learning experience. This test was applied to the students of both groups.

After finishing the observation of the classroom experiences for both groups, the data gathered through these instruments were analyzed quantitatively to identify valuable findings that were then explained qualitatively.

Quantitative analysis methods

Given the experiment structure (i.e., randomized controlled trial) and the nature of instruments responses (i.e., frequency of selecting each category in an ordinal variable), one way to test statistical differences between two groups (treatment vs control, or treatment before implementation vs treatment during implementation) is using the Chi-square test. This is a nonparametric test used to analyze group differences in variables measured in nominal or ordinal levels. Given any categorical variable, the null hypothesis in this test is that there is no difference between groups, and the alternative hypothesis is that there is. Unfortunately, this test is not appropriate when the sample size is not large enough, which sometimes allows that in more than $20 \%$ of the contingency table cells the expected value is less than 5 . In the case study reported in this paper, this Chi-square test assumption is not met, so Exact Tests are more appropriate. Fisher Exact Test and Unconditional Exact Tests may be considered, however, it is well demonstrated that the latter are statistically more powerful than the former [14]. Moreover, there is a significant difference on the assumptions between these two type of tests. Fisher Exact Test assumes that both row and column margins of contingency tables are fixed, which means that it is assumed that group sizes and total sum of counts in each category are fixed. In contrast, the 
Unconditional Exact test, using the Binomial model, assumes that row or column margins, but not both, are fixed, which is appropriate for randomized controlled trial as the one conducted in this case study: group sizes are fixed, but total sum of counts in each category is not fixed [15].

Thus, all comparisons between the two groups were conducted using the Unconditional Exact test with the Binomial model. In the cases where this test cannot be used, for example when one column or row in the contingency table is full of zeros, the Fisher Exact Test is employed as the only alternative. All tests were developed in R, using the "Exact" package [15].

\section{Results}

\subsection{The redesign of the learning experience}

Among the initial reflections that led to the redesign of the classroom experience are the difficulties of mathematics learning that the instructor has identified recurrently in the majority of engineering students registered in the Algebra and Functions course. In this case, the instructor focused mostly on rational functions, mentioning that the difficulties that are most present in students are related to the following aspects: meaning of the concept of rational functions, interpretation of the domain and rank, the role of the asymptotes in the notion of infinity, identification of variations in their graphic register, relations between the graphic and symbolic register, verbal register and their identification in real phenomena.

The learning objectives involved in the redesign of the learning experience are the following:

- LO1: Numerical and symbolic treatment of the rational function from its graphical variations

- LO2: Conceptual communication about the rational function and its characteristics

- LO3: Analytical and conceptual interpretation of the rational function from its development in a real context (verbal register)

- LO4: Description of existing variations in a real situation from the graphic representation of a rational function

- LO5: Algebraic representation of a rational function from its graphic representation

These objectives are aligned with the seven competencies of the PISA framework [12]: Reason and argue, communicate, model, state and solve problems, represent, symbolic language, use aids and tools. For this redesign, whose central interest was to plan a learning experience based on the needs observed by the instructor in the students' context, special emphasis was given to the skills of modeling, communication, problem solving and the use of technological resources.

Table 1 summarizes the main learning activities defined for the redesigned learning experience.

The new didactic strategies focused on collaborative work, individual and group assignments, as well as dissemination and justification of activities using discursive processes in the classroom. The latter, in order to contribute to the development of communication processes. The proposed approach for the evaluation was directed to promote greater feedback and support from the instructor. 
Table 1 - Learning activities and their relationship with learning objectives

\begin{tabular}{lll}
\hline Situations & Learning Objectives (LO) & Learning Activity \\
\hline S1. & LO1 & $\begin{array}{l}\text { Students make use of GeoGebra to study the parameters present } \\
\text { in the graphic register of the rational function; besides } \\
\text { interpreting their transformations in the plane. }\end{array}$ \\
\hline S2. & LO1, LO5 & $\begin{array}{l}\text { Students make use of GeoGebra to establish relationships } \\
\text { between the symbolic and the graphic representations; also, to } \\
\text { interpret the domain and range of a function from the meaning } \\
\text { of its asymptotes. }\end{array}$ \\
\hline S3. & LO2,LO5 & $\begin{array}{l}\text { The relationship between the symbolic and the algebraic is } \\
\text { retaken, in addition to leading students to reflect on the } \\
\text { conceptual meaning of the rational function. }\end{array}$ \\
& $\begin{array}{l}\text { Students must use GeoGebra to explain the mathematical } \\
\text { concept of rational function, from algebraic and symbolic } \\
\text { representations }\end{array}$ \\
\hline S4. & $\begin{array}{l}\text { Students must identify and explain the concept of rational } \\
\text { function in a real phenomenon, using GeoGebra to defend their } \\
\text { arguments and interpretations. }\end{array}$ \\
\hline
\end{tabular}

\section{Effects of the new learning experience on the learning environment}

Table 2 shows the impact of the new learning experience on selected aspects of the learning environment. In the new learning experience, the instructor continuously reflected on the context in which the students' learning is developed, mathematically, socially and institutionally. Based on this, she planned the classes differently to the conventional way of doing it. The instructor gave privilege to the learning goal and great ideas, proposing activities focused on the strengthening of the processes and skills in the mathematics (cf. Table 1).

Regarding the learning activities present before the redesign, they lacked planning and sequence, and focused mainly on objectives that aimed at acquiring math contents rather than developing competencies. Before the redesign of the learning experience, the activities in the classroom tended to focus on the magisterial and individual work, with very little participation of students in classroom discussions. During the implementation, the instructor gave greater importance to the work in the classroom than to the work at home, which gave students the opportunity to complete their work with the help of their peers and the professor. Class planning was crucial to prioritize learning objectives, and to relate previous concepts and processes from one activity to another.

Promoting collaborative work was one of the novel strategies in the new learning experience. This increased the engagement of students that had little participation in the conventional classes. Also, significant improvements were seen in the teacher's interventions and the discussions that emerged from each learning activity. 
Table 2 - Effects of the redesigned learning experience on selected aspects of the learning environment

\begin{tabular}{|c|c|c|}
\hline Elements & Before & During \\
\hline Professor critical reflection & No & Yes \\
\hline Learning objectives & $\begin{array}{l}\text { Focused on contents } \\
\text { Not aligned }\end{array}$ & Competency alignment \\
\hline Learning activities & $\begin{array}{l}\text { Guide texts exercises } \\
\text { More work at home }\end{array}$ & $\begin{array}{l}\text { Design } \\
\text { Adaptation } \\
\text { More work in the classroom } \\
\text { Activities in sequence }\end{array}$ \\
\hline Strategies & $\begin{array}{l}\text { Magisterial } \\
\text { Individual work } \\
\text { Participation is minimal } \\
\text { Fewer support } \\
\text { Fewer discussions in the } \\
\text { classroom (peers, teacher). }\end{array}$ & $\begin{array}{l}\text { Collaborative work } \\
\text { Individual support } \\
\text { The participation is higher } \\
\text { More discussions in the classroom } \\
\text { (peers, teacher). }\end{array}$ \\
\hline Resources & $\begin{array}{l}\text { Reduced physical space } \\
\text { (classroom) } \\
\text { Individual work tables } \\
\text { Lack of technological resources }\end{array}$ & $\begin{array}{l}\text { Larger physical space } \\
\text { (classroom). } \\
\text { Group work tables } \\
\text { Use of technological resources } \\
\text { (GeoGebra) }\end{array}$ \\
\hline Evaluation & $\begin{array}{l}\text { Summative } \\
\text { No use of rubrics. } \\
\text { Accumulative evaluations }\end{array}$ & $\begin{array}{l}\text { Formative } \\
\text { Use of Rubrics } \\
\text { Evaluations during the process }\end{array}$ \\
\hline
\end{tabular}

Regarding resources and physical spaces, the instructor chose a more spacious and comfortable room. The new space provided important elements that facilitated collective work and discussion, and the close interaction of the professor with all students. On the other hand, the inclusion of a technological resource of mediation in the class allowed students to have an active approach to the graphic representation of the rational function, and to gain confidence because the tool helps them solve problems with a higher level of complexity.

Lastly, in the redesigned learning experience, the evaluation focused more on continuous feedback and on the opportunity for students to reflect on their mistakes and improve. However, although significant changes were observed, it was evident the instructor's difficulty when providing such feedback more effectively and using rubrics to evaluate student performance during the development of the activities. Variables associated with these difficulties are time constraints and the secondary effects that are generated by changes in evaluation strategies. 


\subsection{Reflections by the mentored instructor}

The instructor highlights the redesign stage as one of the most significant ones. She highlights the guidance given with practical and pedagogical references that enriched the design of her new learning experience, as the following reflection shows:

"One of the biggest challenges in redesigning is to think about the proposal that will be put into action, which must be aligned not only with the teacher's experience but also with some theoretical referents that support what you want to do."

Another aspect that the instructor highlights from the redesign stage was the change achieved from her practice in the classroom as well as from her teaching. She highlights the orientations provided from the mentoring to help her reflect on resources, time, and ways in which she could improve the learning environment for students. The reflection of the instructor was as follows:

"When you're in the process of creating daily class activities you take the time to plan what you'll take to the classroom, but not in such a detailed way as it was after planning the redesign. In these processes you take the time to think about the resources to use, analyze your ideas and think more about the student and the possibilities of your answers. You take the time to analyze all the aspects that, from your role as a teacher, you can handle to offer the student the best conditions to learn."

With respect to the implementation, the instructor emphasizes the role of the reflective professor who continues to review, adjust and make changes in their practice during its development. She goes beyond the redesign, and considers the learning environment that may be generated by her pedagogical practices, in order to adjust what it is required to assure the purpose of the experience. The reflection of the instructor was as follows:

"The four activities that would be implemented were considered ready before the implementation, but once the first activity was done with the students, the next activities were modified since the first situation, once implemented, was not completed totally due to the lack of time, which allowed me to gain experience and to slightly modify the following activities. Some exercises were selected from the activity that could be omitted to optimize time without losing sight of the goal of the activity. The first section of the intervention was crucial in order to make decisions about the development of the other activities, as it gave me a clue about what to omit, what to add and what to modify, and those changes were very positive."

The instructor's reflections about the learning environment show that professor-student and student-student communication channels began to be established beyond the content, fostering teamwork and other types of strategies, such as feedback and co-evaluation between pairs. The reflection was the following:

"It is nice to know the opinions of students regarding their feelings during the interventions, to hear from them that the change of space, physical adaptation of the room, the presentation of the activities and the way in which the activities were developed allowed them to understand and develop the purpose of each of the sections. For the group as a whole, it was very satisfying to see the disposition and the teamwork of the students, it is comforting for the teacher to see the great work developed [...] The distribution of space allowed a more personalized approach with the groups, since it allowed me to share with each one of them and know a little more closely their learning process and the justification of each of the solution processes, which allowed me to give more effective feedback." 
Concerning the reflection on the students' performance, and the achievement of the learning objectives and purposes of the classroom experience, it is evident that the difficulties that initially gave rise to the study problem identified by the instructor for the Algebra and Functions course are being overcome. The instructor mentions in her reflection that:

"Comparing the presentation and development of the mathematical object rational functions with previous semesters, it was possible, in this activity, to bring the student closer to the algebraic and graphical interpretation to the rational function, they established a better relationship between the domain of the function, the graphic representation and the algebraic representation. Most students managed to identify the asymptotes both vertically and horizontally (if they existed) in the algebraic representation of a rational function, I consider it to be a great advance and it was one of the objectives of the activities."

What the instructor's participation in the project taught her was particularly the importance of connecting and finding relationships between mathematical concepts, having clear learning purposes and objectives that she also shares with her students, which shows an intention to promote formative evaluation in the classroom. The instructor also began to identify that she can have a co-apprentice role for her students. The instructor's reflection about what she learned in the case study was the following:

"Every time I plan my next class, I try, as much as possible, for the student to find a relationship with the previous topics, to feel that each concept that we have seen in the classroom has to be constantly remembered so that it does not conceive a thematic fragmentation. Although each class of the course has a purpose, I keep explaining to the student in an engaging way what the objective of the class is, so that it does not get lost during the way. Now I think more about each activity, workshop, short or mid-term test from the point of view of students, thinking about what they will understand from what is presented to them."

\subsection{Impact on the learning environment}

For each of the 30 aspects evaluated about the learning environment (cf. Table 3), the student had four response options: "Not obvious", "somewhat evident", "evident" and "very evident". The proportion of students who consider that each aspect is very evident among the groups is compared. In 20 out of the 30 aspects, a statistically significant difference between groups can be found (with a confidence level of at least $90 \%$ ), which allows us to conclude that for these 20 aspects the proportion is greater in the treatment group than in the control one. In the remaining 10 , it is not possible to conclude that there is a difference between groups. In this sense, this assessment allows us to conclude that the learning environment is generally more appropriate in the treatment group than in the control one, from the students' perception.

Next, we discuss qualitative evidence identified by the observer to explain the quantitative results of each of the general categories presented in Table 3. 


\section{Table 3 - Impact perceived by students on the learning environment. Instrument: LE-Student}

\begin{tabular}{|c|c|c|c|c|c|}
\hline \multicolumn{5}{|c|}{$\begin{array}{l}\text { Impact on the learning environment from the perspective of the students for } \\
\text { each of the studied groups }\end{array}$} & \multirow{2}{*}{$\begin{array}{l}\text { Description of the evaluated aspects of the learning environment } \\
\text { (from the perspective of the students) }\end{array}$} \\
\hline Aspect & $\begin{array}{l}\text { Treatment Group } \\
\text { (Mentored) }\end{array}$ & $\begin{array}{l}\text { Control Group } \\
\text { (Non-mentored) }\end{array}$ & p-value & $\begin{array}{l}\text { Significance } \\
\text { Level }\end{array}$ & \\
\hline \multicolumn{5}{|c|}{ A: Learning environment and student needs } & A: Learning environment and student needs \\
\hline A1 & $77,78 \%$ & $21,74 \%$ & 0,0003 & **** & A1: I have opportunities to learn through activities that take into account my particular needs \\
\hline A2 & $68,42 \%$ & $29,17 \%$ & 0,0119 & ** & A2: I have access to classroom discussions, technology, resources and personalized mentoring \\
\hline $\mathrm{A} 3$ & $73,68 \%$ & $41,67 \%$ & 0,0400 & ** & A3: I know course rules and I think that they are fair, clear and applied \\
\hline \multicolumn{5}{|c|}{ B: Engagement } & B: Engagement \\
\hline B1 & $73,68 \%$ & $29,17 \%$ & 0,0040 & **** & B1: I know and Im committed to meet the expectations established by my professor \\
\hline B2 & $63,16 \%$ & $20,83 \%$ & 0,0058 & *** & B2: I consider that the assigned activities are challenging but achievable \\
\hline B3 & $84,21 \%$ & $16,67 \%$ & 0,0000 & *** & B3: I find the examples used by my professor highly useful for my learning process \\
\hline B4 & $52,63 \%$ & $8,33 \%$ & 0,0012 & $* * *$ & B4: I actively participate in activities that imply rigorous and valuable discussions \\
\hline B5 & $57,89 \%$ & $29,17 \%$ & 0,0651 & * & B5: I answer questions by connecting concepts and synthesizing general ideas \\
\hline \multicolumn{5}{|c|}{ C: In-classroom and out-of-classroom support } & C:In-classroom and out-of-classroom support \\
\hline $\mathrm{C} 1$ & $78,95 \%$ & $25,00 \%$ & 0,0004 & **** & C1: I find the classroom experience as highly valuable for my learning process \\
\hline $\mathrm{C} 2$ & $73,68 \%$ & $50,00 \%$ & 0,1490 & & C2: I show a positive attitude towards my professor, my classmates and in general towards learning \\
\hline $\mathrm{C} 3$ & $47,37 \%$ & $33,33 \%$ & 0,3750 & & C3: I take risks when sharing my ideas and opinions, without fear of receiving negative comments \\
\hline $\mathrm{C} 4$ & $63,16 \%$ & $41,67 \%$ & 0,1795 & & C4: I receive appropriate support to understand concepts, complete assignments and achieve learning goals \\
\hline $\mathrm{C} 4 \mathrm{a}$ & $63,16 \%$ & $37,50 \%$ & 0,1054 & & C4a: I request the support of my professor to understand concepts, complete assignments and achieve learning goals \\
\hline C5 & $63,16 \%$ & $50,00 \%$ & 0,5153 & & C5: I look for the support of my classmates to understand concepts, complete assignments and achieve learning goals \\
\hline $\mathrm{C} 6$ & $78,95 \%$ & $33,33 \%$ & 0,0030 & **** & C6: I received additional support from my professor, when required \\
\hline \multicolumn{5}{|c|}{ D: Active Learuing } & D: Active learning \\
\hline D1 & $47,37 \%$ & $4,17 \%$ & 0,0008 & **** & D1: I engage myself in classroom discussions \\
\hline D2 & $42,11 \%$ & $16,67 \%$ & 0,0717 & * & D2. I make connections between the concepts learned in the course and real-life situations \\
\hline D3 & $47,37 \%$ & $16,67 \%$ & 0,0344 & ** & D3: I actively participate in the learning activities of the course \\
\hline \multicolumn{5}{|c|}{ E: Formative assessment } & E: Formative assessment \\
\hline E1 & $72,22 \%$ & $14,29 \%$ & 0,0003 & **** & E1: My professor shows interest in my individual progress / learning \\
\hline E2 & $61,11 \%$ & $14,29 \%$ & 0,0024 & **** & E2: I act upon my professor's feedback to improve my learning \\
\hline E3 & $27,78 \%$ & $23,81 \%$ & 0,8249 & & E3: I can communicate verbally my understanding of the studied lessons \\
\hline E4 & $66,67 \%$ & $33,33 \%$ & 0,0429 & ** & E4: I understand clearly the way how my learning progress is evaluated by my professor \\
\hline E5 & $77,78 \%$ & $33,33 \%$ & 0,0055 & *** & E5: My professor gives me opportunities to improve my learning based on her feedback \\
\hline \multicolumn{5}{|c|}{ F: Interaction with others } & F: Interaction with others \\
\hline F1 & $83,33 \%$ & $52,38 \%$ & 0,0482 & *** & F1: I communicate in a respectful manner with my professor and classmates \\
\hline F2 & $55,56 \%$ & $50,00 \%$ & 0,7660 & & F2: I follow the course rules and work effectively in teams \\
\hline F3 & $61,11 \%$ & $25,00 \%$ & 0,0338 & ** & F3: My professor allows us to take breaks before transitioning from one activity to another one \\
\hline F4 & $47,06 \%$ & $19,05 \%$ & 0,0772 & * & F4: I contribute significantly when working in teams \\
\hline \multicolumn{5}{|c|}{ G: Use of teclunology } & G: Use of tecluology \\
\hline G1 & $77,78 \%$ & $66,67 \%$ & 0,5286 & & G1: I use technology to gather, evaluate, and/or use information for learning \\
\hline $\mathrm{G} 2$ & $55,56 \%$ & $42,86 \%$ & 0,5286 & & G2: I use technology to conduct research, solve problems, and/or create original works for leaming \\
\hline $\mathrm{G} 3$ & $61,11 \%$ & $47,62 \%$ & 0,5286 & & G3: I use technology to communicate and work collaboratively for learning \\
\hline
\end{tabular}




\section{$\underline{\text { A: Learning environment and student needs }}$}

Table 4 summarizes the main aspects highlighted by students of the treatment and control group, as well as the evidence gathered by the observer during the observed classes. Student aspects were identified from the interviews conducted by the observer and the comments included in the LE-Student instrument.

\section{Table 4 - Detail of students' and observer's perception about the impact on the learning environment - student needs}

\begin{tabular}{l|l}
\hline \multicolumn{1}{c|}{$\begin{array}{c}\text { Student Perceptions } \\
\text { Treatment Group (TG) }\end{array}$} & \multicolumn{1}{c}{$\begin{array}{c}\text { Student Perceptions } \\
\text { Control Group (CG) }\end{array}$} \\
\hline $\begin{array}{l}\text { Most students indicated that, after the } \\
\text { implementation, the support provided by their } \\
\text { professor was better and they had better } \\
\text { opportunities to participate in the discussions that } \\
\text { took place through the classroom activities. }\end{array}$ & $\begin{array}{l}\text { Most students indicate that the support provided by } \\
\text { their instructor was remarkable better right before } \\
\text { exams. }\end{array}$ \\
$\begin{array}{l}\text { The instructor was clear on the instructions and } \\
\text { expectations for each of the assigned activities, and } \\
\text { this was coherent with what really happened with } \\
\text { each of the activities. }\end{array}$ & $\begin{array}{l}\text { Although there were opportunities for extensive } \\
\text { discussions and participation in the classroom, some } \\
\text { students preferred not to do so for fear of making } \\
\text { mistakes. }\end{array}$ \\
\hline
\end{tabular}

\section{Observer comments}

It was observed that it was very frequent that the mentored professor took the initiative to ask students about their work. In contrast, the non-mentored professor answered questions as long as the students demanded it.

The non-mentored instructor usually promoted the participation of the same students.

The discussions were extensive in the discourse of the non-mentored professor; however, these were not part of a classroom experience design based on the critical reflection of the instructor, as it was the case for the mentored professor.

TG students had access to computers to use GeoGebra to work individually and collectively. In contrast, in the CG, students had no access to computers, and although some accessed through their smartphones, most of the times was the instructor the only one using GeoGebra to make explanations to the students, while they listened passively.

It is evident the positive impact that the redesign of the learning activities had on the learning environment from the perspective of the student's particular needs. For instance, component A1 for the TG outperformed the CG by more than $50 \%$ (77.78\% vs. $21.74 \%)$. The observer identified that this is because students felt more supported by their professor, which was the result of the new structure of the pedagogical activities and the new physical space (classroom).

\section{B: Engagement}

Table 5 presents most relevant quality evidence on what respects to student engagement in both groups. 


\section{Table 5 - Detail of students' and observer's perception about the impact on the learning environment - engagement}

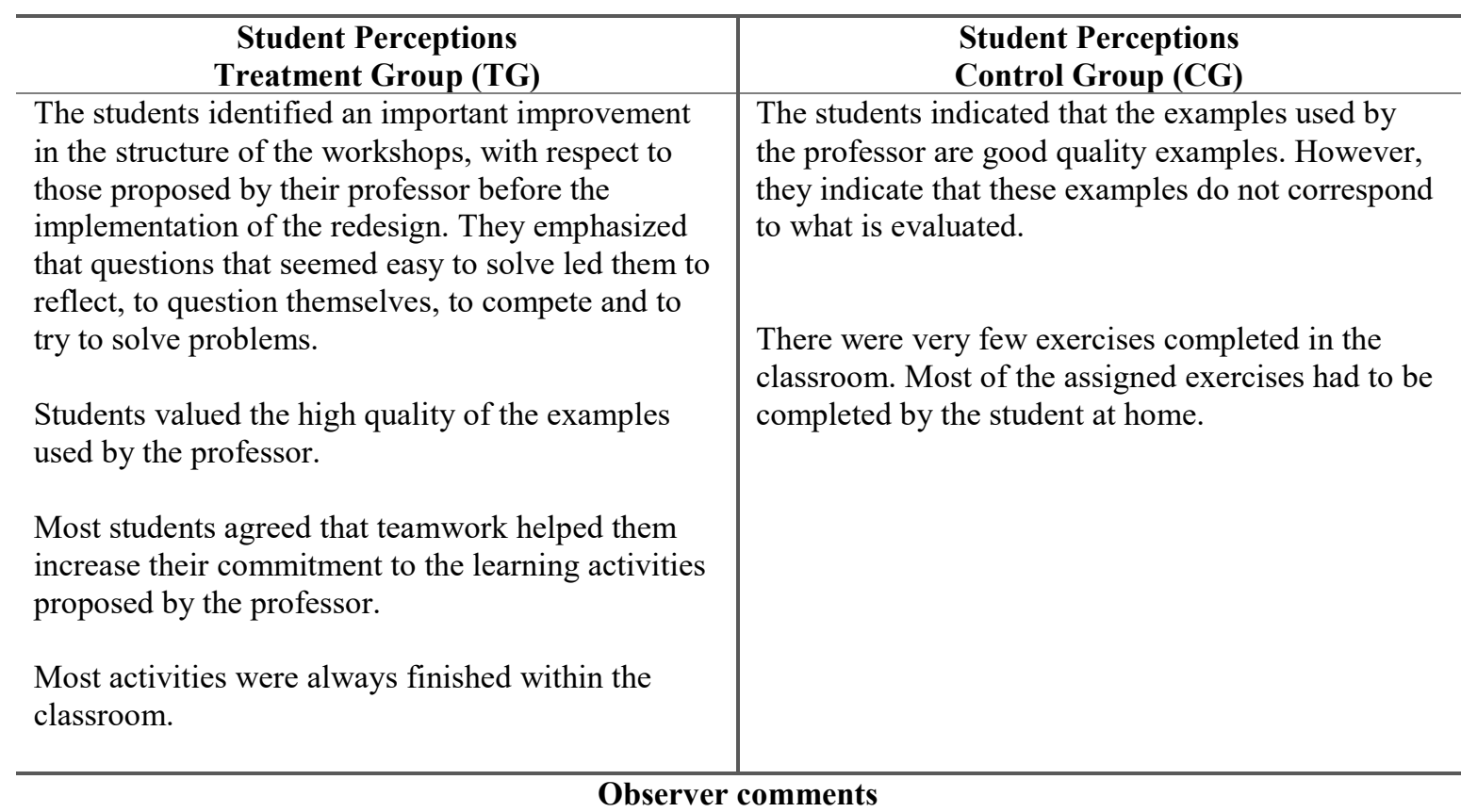

In the TG, teamwork improved the participation of those students that usually prefer not to participate in classroom activities. Collective learning experiences and discussions helped students to improve the comprehension of concepts. Teams were defined by the professor, based on student characteristics.

Teamwork in the CG did not look as well planned as in the case of the mentored professor. As a result, the interest of some students in participating was negatively affected. Some students got distracted, and some others payed attention but assuming passive attitude. Thus, there were not collective discussions around mathematics concepts. The professor did not give clear instructions about team-based activities.

The mentored professor payed special attention to the design of examples coherent with the sequence of learning activities. This helped students advance in the next steps of the learning sequence.

Teamwork resulted crucial to increase student engagement. The absence of effective team-based activities was one of the main problems for assuring engagement in the CG. Math concept discussions resulted more effective when they were properly integrated into learning activities attractive to the students. In the CG, discussions were disconnected from the learning activities and examples proposed by the professor. Students perceived a superior quality in the learning activities proposed by the mentored professor, which is confirmed by the significant difference existing between the answers of students enrolled in the TG vs. the students in the CG, particularly for components B1-B4.

\section{C: In-classroom and out-of-classroom support}

The results presented in Table 3 suggest that with respect to the support given to students in and out of the classroom, there were significant improvements in the treatment group for aspects $\mathrm{C} 1$ (the value of the classroom experience for the learning process), and C6 (additional support 
received from the professor), which is coherent with the qualitative feedback provided by the students and the observer (cf. Table 6).

\section{Table 6 - Detail of students' and observer's perception about the impact on the learning environment - support}

\begin{tabular}{|c|c|}
\hline $\begin{array}{l}\text { Student Perceptions } \\
\text { Treatment Group (TG) }\end{array}$ & $\begin{array}{l}\text { Student Perceptions } \\
\text { Control Group (CG) }\end{array}$ \\
\hline $\begin{array}{l}\text { Most student questions were solved in the } \\
\text { classroom. }\end{array}$ & $\begin{array}{l}\text { Students complained about the length of the } \\
\text { assigned activities. Most of them could not be } \\
\text { completed in the classroom. }\end{array}$ \\
\hline $\begin{array}{l}\text { Most learning activities were conducted in the } \\
\text { classroom. }\end{array}$ & $\begin{array}{l}\text { The time in the classroom was insufficient to } \\
\text { answer all questions, so students had to look for }\end{array}$ \\
\hline $\begin{array}{l}\text { Students emphasized on the importance of } \\
\text { classroom learning activities to demonstrate the } \\
\text { accomplishment of level objectives in the midterm. }\end{array}$ & $\begin{array}{l}\text { tutoring hours (usually not with the same professor } \\
\text { of the course), or even for external support (private } \\
\text { instructors, videos on Internet). }\end{array}$ \\
\hline $\begin{array}{l}\text { Most activities were always finished within the } \\
\text { classroom. }\end{array}$ & $\begin{array}{l}\text { Students indicated to depend on the support } \\
\text { provided by the Center for Math Learning } \\
\text { (CAMBAS, for its acronym in Spanish), or other }\end{array}$ \\
\hline $\begin{array}{l}\text { Students valued the additional support received } \\
\text { from the instructor, and the coherence of the } \\
\text { assignments and study materials with respect to the } \\
\text { activities developed in the classroom. }\end{array}$ & $\begin{array}{l}\text { resources external to the University, to get ready for } \\
\text { the exams. Furthermore, they claimed that the only } \\
\text { resource available to be prepared for the midterm } \\
\text { was the catalogue of exercises that must be solved } \\
\text { by themselves before studying each topic with the } \\
\text { professor. These exercises are selected from } \\
\text { textbooks, collectively among all the instructors in } \\
\text { charge of the different sections of the course. } \\
\text { Students complained that the number of exercises is } \\
\text { excessive, thus time is insufficient to get complete } \\
\text { feedback from the instructor. }\end{array}$ \\
\hline
\end{tabular}

Observer comments

All students in both groups value better the usefulness of the learning activities conducted in the classroom with the guide of the professor.

For both groups, the observer identified a supportive learning environment among students, and between students and the professor.

The higher the number of students in the classroom, the more difficult to assure the quality of the feedback provided by the professor. The mentored instructor informed that having 20 students is significantly better than 27 or 30, as it has happened in her former sections of Algebra and Functions.

\section{D: Active learning}

Table 7 presents qualitative evidence about the improvement of the learning environment in what respects to active learning. 


\section{Table 7 - Detail of students' and observer's perception about the impact on the learning environment - active learning}

\begin{tabular}{l|l}
\multicolumn{1}{c|}{\begin{tabular}{c}
\multicolumn{1}{c}{$\begin{array}{c}\text { Student Perceptions } \\
\text { Treatment Group (TG) }\end{array}$} \\
$\begin{array}{l}\text { Students claimed that the professor motivates their } \\
\text { participation in classroom collective discussions. }\end{array}$
\end{tabular}} & $\begin{array}{l}\text { Students informed that there were very few team- } \\
\text { based discussions in the classroom. Most } \\
\text { discussions are led by the professor. }\end{array}$ \\
$\begin{array}{l}\text { They valued learning active strategies as they help } \\
\text { them be more autonomous. However, they } \\
\text { emphasized on the importance of being guided by } \\
\text { the professor. }\end{array}$ & $\begin{array}{l}\text { They valued active learning strategies as they help } \\
\text { them be more autonomous. However, they } \\
\text { emphasized on the importance of being guided by } \\
\text { the professor. }\end{array}$ \\
$\begin{array}{l}\text { During the implementation of the case study, in- } \\
\text { classroom team-based discussions became more } \\
\text { frequent. }\end{array}$ & $\begin{array}{l}\text { Students informed that the level of commitment to } \\
\text { participate in team-based activities is different } \\
\text { among the students of the course. }\end{array}$ \\
\hline $\begin{array}{l}\text { It was observed a better disposition to participate in the proposed in-classroom learning activities in the } \\
\text { students of the TG. }\end{array}$ \\
\hline
\end{tabular}

One possible cause for achieving a better disposition from students in the TG to participate in active learning activities could have been that math concepts were carefully integrated into the activities proposed by the mentored instructor.

\section{E: Formative Assessment}

Table 8 summarizes perceptions about formative assessment.

Table 8 - Detail of students' and observer's perception about the impact on the learning environment - formative assessment

\begin{tabular}{l|l}
\multicolumn{1}{c|}{\begin{tabular}{c}
\multicolumn{1}{c}{$\begin{array}{c}\text { Student Perceptions } \\
\text { Treatment Group (TG) }\end{array}$} \\
$\begin{array}{l}\text { The professor made sure to visit every team when } \\
\text { working in the classroom to address all students' } \\
\text { questions or concerns. }\end{array}$
\end{tabular}} & $\begin{array}{l}\text { The quality of the instructor's feedback was not the } \\
\text { same for all students. }\end{array}$ \\
$\begin{array}{l}\text { They valued the quality of the feedback given by } \\
\text { the professor, which helped them obtaining better } \\
\text { results in the assignments and midterm. }\end{array}$ & $\begin{array}{l}\text { The instructor's feedback improved right the week } \\
\text { before the midterm. }\end{array}$ \\
& $\begin{array}{l}\text { The feedback received from the instructor was not } \\
\text { very useful to understand where they were failing } \\
\text { and thus improve accordingly. }\end{array}$ \\
\hline
\end{tabular}

Observer comments

None of the instructors gave special attention to the verbal explanation of the concepts that the students learned.

Students in the TG demonstrated to know better about the evaluation strategies to be used by the professors. This was because the professor discussed the rubric in light of learning objectives, several times during the implementation.

During the observed classes, the students of both groups received good quality feedback by the professor, although it was much better and better perceived in the TG. 


\section{$\underline{F: \text { Interaction with others }}$}

Table 8 summarizes important qualitative perceptions in what respects to the impact on the interaction with others.

Table 9 - Detail of students' and observer's perception about the impact on the learning environment - interaction with others

\begin{tabular}{l|l}
\multicolumn{1}{c|}{\begin{tabular}{c}
\multicolumn{1}{c}{$\begin{array}{c}\text { Student Perceptions } \\
\text { Treatment Group (TG) }\end{array}$} \\
$\begin{array}{l}\text { Students demonstrated respect and appreciation for } \\
\text { their professor. }\end{array}$
\end{tabular}} & $\begin{array}{l}\text { Students recognized that their professor cares about } \\
\text { them. } \\
\text { All students informed to have a great relationship } \\
\text { with their peers, and to enjoy learning with others. }\end{array}$ \\
$\begin{array}{l}\text { Some students indicated to prefer individual work } \\
\text { over teamwork. }\end{array}$ \\
$\begin{array}{l}\text { Due to time constraints and the length of the } \\
\text { assigned exercises, student informed that in many } \\
\text { cases they were not able to complete all the } \\
\text { activities assigned by the professor. }\end{array}$ \\
\hline
\end{tabular}

Observer comments

Students in the CG could not manage the workload of the course, whereas in the TG time was enough to develop all the activities assigned by the professor.

Rules to develop learning activities were clearer in the TG.

All students in the TG felt confident about interacting with their professor. In contrast, in the CG several of the students were observed shy and with a lack of initiative or confidence to interact with the professor.

Comments included in Table 9 explain the significant difference existing in what respects to the quality of interactions between the two groups.

\section{G: Use of technology}

All students indicated to enjoy the use of technology in math courses. Indeed, the quantitative results presented in Table 3 show no significant differences between the two groups in what respects to the use of technology (GeoGebra). Nevertheless, the observer and the students' interviews indicate that in the case of the $\mathrm{CG}$, the professor was the one who was actively engaged in the use of the tool as a support for her explanations in the classroom, whereas in the TG all students used it in several of the learning activities developed in the classroom.

\section{Level of attainment of learning objectives}

The closure test measured the level of attainment of each student in each component at the end of the intervention in the treatment group, in such a way that it would be possible to compare the performance of the students in the treatment and control group. The results presented in Table 10 show that the proportion of students with a deficient level of attainment for objectives LO2, LO3 and LO5 is statistically lower in the treatment group than in the control one (cf. right side of Table 10). In the other two components, it was not possible to show a statistically significant difference. Furthermore, for components LO1, LO2 and LO5, the proportion of students in 
proficient or outstanding performance is statistically greater in the treatment group than in the control group (cf. left section of Table 10). In the other two components, it was not possible to show a statistically significant difference. In this sense, these results suggest that the intervention positively influenced the treatment group, since it was possible to show that the performance is never lower than that of the students of the control group in each of the components and, in addition, in almost all (4 out of 5), the performance is better.

\section{Table 10: Proportion of students of each group obtaining the highest (left side) and lowest (right side) levels of attainment in the learning objectives associated with the redesigned learning experience}

\begin{tabular}{|c|c|c|c|c|c|c|c|c|c|}
\hline \multicolumn{5}{|c|}{$\begin{array}{c}\text { Proportion of students with an attainment level of outstanding or } \\
\text { proficient in the learning objectives associated with the redesigned } \\
\text { learning experience (Rational Function), for each group }\end{array}$} & \multicolumn{5}{|c|}{$\begin{array}{l}\text { Proportion of students with an attainment level of deficient in the } \\
\text { learning objectives associated with the redesigned learning experience } \\
\text { (Rational Function), for each group }\end{array}$} \\
\hline $\begin{array}{l}\text { Learning } \\
\text { Objective }\end{array}$ & $\begin{array}{c}\text { Treatment Group } \\
\text { (Mentored) }\end{array}$ & $\begin{array}{l}\text { Control Group } \\
\text { (Non-mentored) }\end{array}$ & p-value & $\begin{array}{c}\text { Significance } \\
\text { Level }\end{array}$ & $\begin{array}{l}\text { Learning } \\
\text { Objective }\end{array}$ & $\begin{array}{c}\text { Treatment Group } \\
\text { (mentored) }\end{array}$ & $\begin{array}{l}\text { Control Group } \\
\text { (Non-mentored) }\end{array}$ & p-value & $\begin{array}{c}\text { Significance } \\
\text { Level }\end{array}$ \\
\hline LO1 & $36,36 \%$ & $8,00 \%$ & 0,0199 & $* *$ & LO1 & $22,73 \%$ & $44,00 \%$ & 0,1609 & \\
\hline $\mathrm{LO} 2$ & $31,82 \%$ & $0,00 \%$ & 0,0024 & $* * *$ & $\mathrm{LO} 2$ & $40,91 \%$ & $100,00 \%$ & 0,0000 & $* * *$ \\
\hline LO3 & $13,64 \%$ & $4,00 \%$ & 0,287 & & LO3 & $45,45 \%$ & $72,00 \%$ & 0,0795 & $*$ \\
\hline LO4 & $40,91 \%$ & $24,00 \%$ & 0,251 & & LO4 & $22,73 \%$ & $40,00 \%$ & 0,243 & \\
\hline LO5 & $31,82 \%$ & $4,00 \%$ & 0,0112 & $* *$ & LO5 & $40,91 \%$ & $80,00 \%$ & 0,0073 & $* * *$ \\
\hline \multicolumn{10}{|c|}{$* * * 99 \% ; * * 95 \% ; * 90 \%$} \\
\hline \multicolumn{10}{|c|}{ LO1: Numerical and symbolic treatment of the rational function from its graphical variations } \\
\hline \multicolumn{10}{|c|}{ LO2: Conceptual communication about the rational function and its characteristics } \\
\hline \multicolumn{10}{|c|}{ LO3: Analytical and conceptual interpretation of the rational function from its development in a real context (verbal register) } \\
\hline \multicolumn{10}{|c|}{ LO4: Description of existing variations in a real situation from the graphic representation of a rational function } \\
\hline \multicolumn{10}{|c|}{ LO5: Algebraic representation of a rational function from its graphic representation } \\
\hline
\end{tabular}

With respect to LO1, students in the treatment group (TG) were able to interact with the numerical and symbolic representations of the rational function, identify all its elements, analyze its behavior with respect to its asymptotes using the graphic representation, and explain the changes in variables and dependency values. In contrast, most students in the control group (CG) could identify the most basic elements of the function from its graphic representation, but presented greater difficulty to explain changes in variables. Regarding the achievement of LO2, TG students were able to explain concepts associated with the rational function in oral and written form, as well as to use counterexamples demonstrating their ability to associate related concepts. The mentored instructor gave special attention to this learning objective, since it was identified in her reflection as one of the most difficult to attain. Finally, with respect to LO5, TG students performed better than CG students in finding the analytical representation of the function from its graphic representation. CG students were able to produce the graphical representation from the analytical model, but not vice versa.

\section{Conclusions}

The fundamental research challenge addressed in this case study relates to the impact that the continuous critical reflection of instructors on their pedagogical practices has on the quality of learning environments. We believe that the better the quality of the learning environment, the higher the academic performance of students. The results presented in this paper provides evidence of how much a learning environment can improve, when instructors reflect on their 
pedagogical practices and propose improvement strategies, accordingly. Nevertheless, one of the main lessons learned is that for instructors to become critical practitioners, institutions must provide them important resources such as proper mentoring and training, as well as enough time to review and improve their teaching strategies. It is important to point out that, despite the mentored professor was guided on how to become a reflective practitioner and how to improve her pedagogical practices, the cornerstone of the case study was the professor's reflection: the improvements she proposed were all derived from the outcomes of her reflective exercise. The mentoring helped her find strategies to realize what she found as improvement opportunities but did not show her what to improve to enhance the learning environment.

The continuous improvement of learning environments has tremendous impact on student academic success. According to Tinto [17], there are five key conditions for student retention and persistence: generation of high expectations, support, frequent and timely feedback, integration within the institution and promotion of learning as a central axis. We conclude this paper by showing how learning environment improvements achieved in the case study have considerable impact on these five conditions.

On the one hand, the results obtained from the application of the LE-Student instrument suggest that after the implementation of the redesigned learning experience, the students of the treatment course know and strive to meet the high expectations set by the instructor. The assigned activities represent a challenge, but at the same time they are achievable, which is closely related to the generation of high expectations. Similarly, students recognize that they understand the way in which they are being assessed. That they receive support and feedback. That such feedback is useful to improve their understanding, promoting opportunities to review and improve the work done, and that the professor shows interest in asking about their progress in individual learning, which is related to offering support and prompting feedback.

On the other hand, the students of the treatment group affirm that they feel involved with their peers and the instructor by contributing in classroom discussions and during group activities, which is linked to the condition that has to do with the integration of the student within the group and the institution. Finally, these students confirm that they feel involved in the learning activities, which is key in terms of learning. According to Tinto, students who are actively involved in the learning process are those who are the most likely to learn and, as a result, to remain in the institution.

The obtained results reinforce the idea that the intervention had a positive effect on learning. Both students and the instructor of the mentored group indicate that learning experiences were positive, and that students showed a positive attitude toward learning and the use of tools / technologies for learning. These elements encouraged students' active participation in the learning process. The closing test suggests that students' performance was superior in 4 out of 5 competences, which also shows the positive effect of the intervention.

\section{References}

[1] L. Lawrence-Wilkes and L. Ashmore, The Reflective Practitioner in Professional Education, MA: Macmillan Publishers Limited, 2014 
[2] B. Larrivee, "Transforming teaching practice: Becoming the critically reflective teacher," Reflective Practice International and Multidisciplinary Perspectives, Vol. 1, no. 3, pp. 293307, 2010. Routledge Taylor \& Francis Group.

[3] L. Bruce. Reflective Practice for Social Workers: A Handbook for Developing Professional Confidence, 1st ed, MA: Open University Press, 2013

[4] S. D. Brookfield, Becoming a Critically Reflective Teacher, The Jossey-Bass higher and adult education series, MA: Jossey-Bass Publishers, 1995.

[5] J. Dewey, How We Think: A Restatement of the Relation of Reflective Thinking to the Educative Process, MA: D.C. Heath and Company, 1933.

[6] J. Dunne, Back to the rough ground: 'Phronesis' and 'techne' in modern philosophy and Aristotle, Notre Dame, MA: University of Notre Dame Pres, 1993.

[7] N. Kellam, A. Babcock, and D. Gattie, "The Engineering Learning Environment: A Proposed Model", ASEE Annual Conference \& Exposition, Conference Proceedings, Pittsburgh, Pennsylvania, USA, Junio 22- 25, 2008, Available in https://peer.asee.org/3779

[8] J.P. Dorman. "Classroom environment research: Progress and possibilities", Queensland Journal of Educational Research, Vol. 18, No. 2, pp. 112-140, 2002.

[9] O. Skovsmose and M. Borda, "Research Methodology and Critical Mathematics Education", in Researching the Socio-Political Dimensions of Mathematics Education, Mathematics Education Library, Col. 35, P. Valero and R. Zevenbergen, Boston, MA: Springer US, 2004, pp. 207-226.

[10] ASOCOLME, 15 encuentro colombiano de matemática educativa (ECME 15). Boletín Asociación de Matemática Educativa ASOCOLME, pp. 4. Available online: http://asocolme.org/publicaciones-asocolme/memorias-ecme [Accessed January, 2019]

[11] Wiggins, G. P., \& McTighe, J., The understanding by design guide to creating high-quality units. ASCD. 2011.

[12] OECD, PISA 2009 Assessment Framework - Key competencies in reading, mathematics and science. Availbale in www.oecd.org/dataoecd/11/40/44455820.pdf [Accessed January, 2019]

[13] AdvancED. Effective learning environment observation tool. Available in https://www.advanc-ed.org/eProveeleot/\#/ [Accessed January, 2019]

[14] R. L. Berger, "Power Comparison of Exact Unconditional Tests for Comparing Two Binomial Proportions," in Institute of Statistics Mimeo Series, No. 2266, Jun. 1994.

[15] P. Calhoun, "Package 'Exact': Unconditional Exact Test", The Comprehensive R Archive Network (CRAN), Oct. 2016.

[16] J. Mason. "Expressing Generality and Roots of Algebra," in: Bernarz N., Kieran C., Lee L. (eds) Approaches to Algebra. Vol 18. Springer, Dordrecht. 
[17] V. Tinto. "Promoting Student Retention Through Classroom Practice." in Conference on Enhancing Student Retention: Using International Policy and Practice, Amsterdam, Netherlands, November 5-7, 2003. 